\title{
Fibrinolytic activity in plasma and urine in chronic renal disease
}

\author{
N. EDWARD, D. P.-G. YOUNG, AND M. MACLEOD \\ From the Department of Medicine, University of Aberdeen
}

The fibrinolytic enzyme system is considered to be important in the removal of pathological deposits of fibrin (Astrup, 1956). In the later stages of renal disease excessive fibrinous exudates are often formed. A defect in the fibrinolytic enzyme system of lung tissue which may be important in the pathogenesis of the fibrinous intra-alveolar exudate which occurs in renal failure has been reported (MacLeod, Stalker, and Ogston, 1962). We describe here the results of a study of the fibrinolytic system in plasma and urine in a group of patients with renal disease.

\section{THE PATIENTS}

Two groups of patients were studied. Fourteen patients had renal disease as shown in the Table. Renal clearance of endogenous creatinine in this group ranged from less than $10 \mathrm{ml}$. to $29 \mathrm{ml}$./minute and the blood urea from 50 to $700 \mathrm{mg}$. $/ 100 \mathrm{ml}$.

\section{TABLE}

Disease

Chronic glomerular nephritis

Chronic pyelonephritis

Polyarteritis nodosa

Nephrosclerosis

Polycystic disease

Renal hypoplasia

Renal infarction (chronic rheumatic heart disease)

Sixteen patients were chosen as hospital controls. None had a disease known to affect the fibrinolytic enzyme system. Age and sex distribution in the two groups were comparable.

\section{METHODS}

Blood samples were taken by clean venepuncture from fasting, rested patients at 9 a.m. Urine specimens were obtained at the same time.

Euglobulin clot lysis times were estimated by the method of Nilsson and Olow (1962).

Plasminogen was measured by caseinolytic assay using a modification of the method described by Norman (1957).

Fibrinogen was determined as fibrin by a modification of the method of Blombäck and Blombäck (1956). After coagulation of the fibrinogen under standard conditions the clot was dissolved in $0.1 \mathrm{~N} \mathrm{NaOH}$ at $100^{\circ} \mathrm{C}$. for 20 minutes and the protein content determined by measuring the extinction at $282 \mathrm{~m} \mu$.

Plasminogen activator in urine was measured by means of unheated fibrin plates prepared by the method of Astrup and Müllertz (1952) as modified by Nilsson and Olow (1962).

Serial dilutions of urine were made with distilled water and fibrinolytic activity was estimated by applying $0.03 \mathrm{ml}$. of each sample, in triplicate, to unheated fibrin plates. A purified preparation of urokinase, also in serial dilutions, was used as a reference standard. The plates were incubated at $37^{\circ} \mathrm{C}$. for 18 hours. The area of lysis was estimated from the product of two diameters at right angles to each other. These values, for both urine and urokinase dilutions, were expressed in square millimetres and plotted on a log-log scale. The fibrinolytic activity of the urine samples was obtained by extrapolation and expressed as units of urokinase. A similar procedure was used by Albrechtsen (1957) to compare the fibrinolytic activity in extracts of various human tissues.

Urine samples from the control and uraemic group were tested for the presence of proteolytic enzymes on fibrin plates which had been heated to $85^{\circ} \mathrm{C}$. for 45 minutes to denature plasminogen, as described by Lassen (1953). Some specimens from patients with renal disease were tested for urokinase inhibition using a standard urokinase solution and unheated fibrin plates.

The clearance of endogenous creatinine was determined using an adsorption method to estimate creatinine in urine and in plasma (Ralston, 1955).

\section{RESULTS}

The values obtained for overall fibrinolytic activity in plasma and the levels of plasminogen and fibrinogen in the two groups of patients are shown in Figure 1.

Control values for euglobulin clot lysis times gave a mean value of 167 minutes (S.D. \pm 45 ). Most of the patients with renal disease had considerably prolonged lysis times with a mean value of 571 minutes (S.D. \pm 376 ).

A mean level of 3.3 units of plasminogen was the same for the control and uraemic groups. It is of interest, however, that the lowest levels of plasminogen, shown in Fig. 1 as open circles, were obtained from patients with the nephrotic syndrome. The 

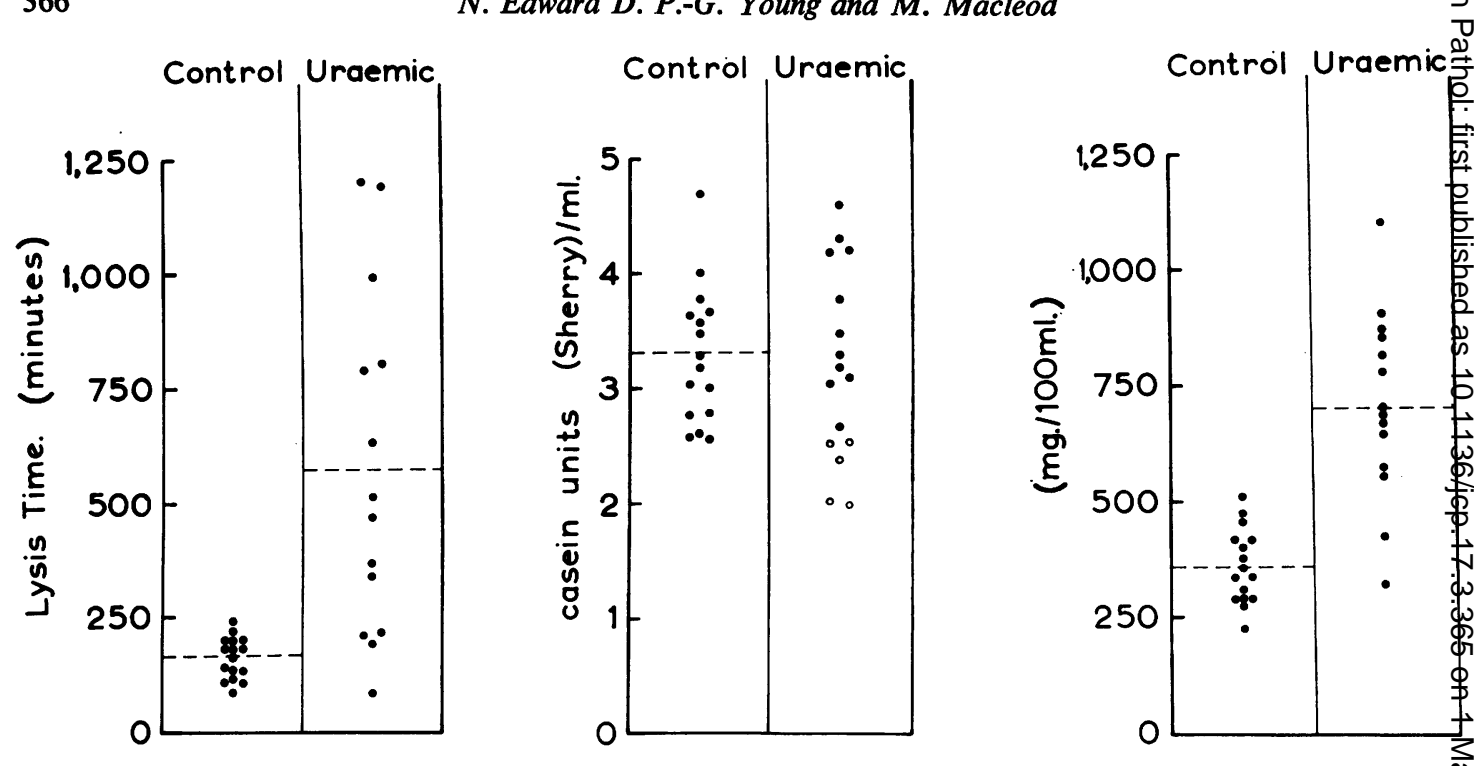

FIG. 1. Values for fibrinolytic activity in plasma and level of plasminogen (col.2) and fibrinogen (col.3) and euglobulim lysis times (col. 1).

mean plasminogen level of 2.3 units in these five patients, three from this study and two additional ones, was significantly less than the values found in the control group and in the remainder of the uraemic group $(\mathbf{P}<0.001)$.

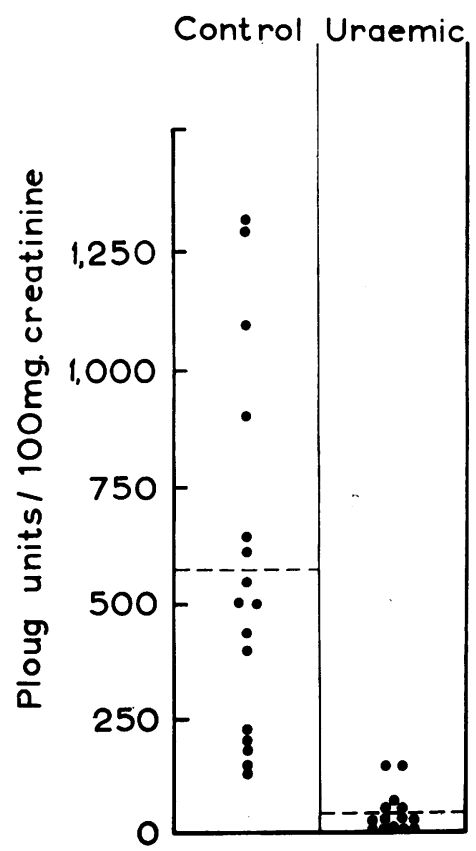

FIG. 2. Fibrinolytic activity in urine.
The mean concentration of fibrinogen in the plasma of uraemic patients was $713 \mathrm{mg} . / 100 \mathrm{~m}$. (S.D. \pm 202$)$. This shows a considerable increase over the mean value in the control group, which wās $361 \mathrm{mg} . / 100 \mathrm{ml}$. (S.D. \pm 80 ).

Fibrinolytic activity in urine is expressed as Ploug units $/ 100 \mathrm{mg}$. creatinine to compensate fot variations in urinary concentration (Fig. 2). There a marked reduction in the activity of plasminogen activator in renal disease. The mean value for this group was 46 units $/ 100 \mathrm{mg}$. creatinine (S.D. \pm 50 ) compared with 575 units $/ 100 \mathrm{mg}$. creatinine (S.D. 390 ) in the controls.

\section{COMMENT}

The proteolytic enzyme plasmin is formed activation of its precursor plasminogen. Fibrin lytic activity in human tissues and body fluids mas be diminished either by deficiency or inhibition $\mathscr{P}$ plasminogen activators or by excessive amounts of antiplasmins.

The euglobulin clot lysis time is mainly, though not entirely, a measurement of plasminogen activas tor. The prolonged lysis times found in patients wi䒘 renal disease indicate a reduction in the overal fibrinolytic activity of the blood.

Studies of blood coagulation have shown increased concentrations of fibrinogen in the plasma of patients with chronic renal disease (Gross, Neith and Mammen, 1958; Egeberg, 1962). The cause of 
this elevation has remained obscure. The concentration of circulating fibrinogen varies inversely with the overall fibrinolytic activity of the blood. The high levels of fibrinogen found in this study may therefore be attributed, at least in part, to diminished fibrinolytic activity in plasma.

The comparatively low level of plasminogen found in the plasma of patients with the nephrotic syndrome is not explained. Plasminogen is associated with the globulin fraction of plasma. It was not demonstrated in urine samples from these patients.

Fibrinolytic activity in normal urine was first described by Macfarlane and Pilling (1947). Williams (1951) suggested from his studies that this was due not to a proteolytic enzyme but to an activator of plasminogen. The activator urokinase was later demonstrated (Astrup and Sterndorff, 1952) although its origin is still not definitely known. Low excretion rates of urokinase have been reported in the urine of patients with cardiac failure, carcinomatosis, and uraemia (Smyrniotis, Fletcher, Alkjaersig, and Sherry, 1959).

The low fibrinolytic activity found in the urine of patients with renal disease could be due either to diminished excretion of urokinase or to excessive amounts of inhibitors. Urokinase inhibition was demonstrable in urine specimens only when activator activity was completely lacking. The nature and measurement of inhibitors require further study.

The marked overall depression of fibrinolytic activity which was found in this investigation may be concerned with the high concentrations of fibrinogen in plasma, the production of fibrinous deposits on serous membranes such as the pericardium and the fibrinous exudates, some hyalinized and undergoing fibroblastic organization, which are commonly found in chronic renal disease.

\section{SUMMARY}

Fibrinolytic activity in plasma and urine was estimated in 14 patients with chronic renal disease of varying severity and in 16 hospital controls.

Patients with renal disease showed a prolongation of the euglobulin clot lysis time and a marked increase in the concentration of circulating fibrinogen. Patients with the nephrotic syndrome had low plasminogen levels in the plasma.

Fibrinolytic activity in urine was either absent or considerably diminished. Plasminogen activators were found to be inhibited in some specimens.

The overall depression of fibrinolytic activity may be important in the production of the excessive fibrinous exudates of chronic renal disease.
This research programme has been supported by a grant from the Scottish Hospital Endowments Research Trust.

\section{REFERENCES}

Albrechtsen, O. K. (1957). Brit. J. Haemat., 3, 284.

Astrup, T. (1956). Lancet, 2, 565.

-, and Müllertz, S. (1952). Arch. Biochem., 40, 346.

- and Sterndorff, I. (1952). Proc. Soc. exp. Biol. (N.Y.), 81, 675. Blombäck, B., and Blombäck, M. (1956). Ark. Kemi., 10, 415.

Egeberg, O. (1962). Scand. J. clin. Lab. Invest., 14, 163.

Gross, R., Neith, H., and Mammen, E. (1958). Klin. Wschr., 36, 107. Lassen, M. (1953). Acta physiol. scand., 27, 371.

Macfarlane, R. G., and Pilling, J. (1947). Nature (Lond.), 159, 779.

MacLeod, M., Stalker, A. L., and Ogston, D. (1962). Lancet, 1, 191. Nilsson, I. M., and Olow, B. (1962). Acta chir. scand., 123, 247.

Norman, P. S. (1957). J. exp. Med., 106, 423.

Ralston, M. (1955). J. clin. Path., 8, 160.

Smyrniotis, F. E., Fletcher, A. P., Alkjaersig, N., and Sherry, S. (1959). Thrombos. Diathes. haemorrh. (Stuttg.), 3, 257.

Williams, J. R. B. (1951). Brit. J. exp. Path., 32, 530.

MR. FORREST described the treatment with streptokinase of a 3-month-old infant with congenital hydronephrosis in whom an attempt at plastic repair of the malformation had been unsuccessful. Pus was drained by a nephrostomy tube but after four weeks of continuous drainage and irrigation the urine still contained clumps of pus. Proteus and pyocyaneus were grown on urine culture. Instillation of streptokinase $(100,000$ units $/ 10 \mathrm{ml}$.) was then started. After six treatments given on alternate days the urine was clear to the naked eye but still contained protein. After nine instillations only a trace of protein was present. When treatment was discontinued for four days clumps of pus began to reappear. A total of 18 treatments was given over five weeks. No toxic effects were observed.

DR. JAMES stated that at the Westminster Hospital they had treated three patients with streptokinase for clot retention following prostatectomy. The treatment was effective after about an hour, so that the clots could be dislodged and washed out. He was able to confirm Dr. Edward's observations on fibrinolysis in uraemic patients, as he had found definite lengthening of the lysis time as measured by the Fearnley method.

DR. MCNICOL stated that he had made similar observations in Glasgow on 40 patients with uraemia and 40 matched controls. The uraemic patients had prolonged euglobulin lysis times and raised plasma fibrinogen levels. There was, however, no correlation between euglobulin lysis time and fibrinogen levels, or between the former and the blood urea level. Lysis times failed to correlate with plasminogen levels in this group and also failed to do so with the diagnosis, in that some patients with renal failure showed reduced fibrinolytic activity, whereas others did not. He asked whether Dr. Edward's patients showed correlation between the euglobulin lysis time and level of urokinase inhibitor, as in his series there had been a rough but by no means rigid correlation.

DR. EDWARD agreed with the general lack of correlation found by Dr. McNicol, excepting perhaps in patients with acute renal failure who produced a fairly typical pattern after a few days. His information about inhibitors was limited because of the lack of a satisfactory method of measurement. However, they had found that patients 
whose euglobulin lysis times are in the region of three to four hours had just measurable inhibitor levels, whereas patients whose lysis times were 24 hours or longer tended to have very high inhibitor levels.

MR. ECKSTEIN, referring to Mr. Forrest's paper, said that there was a group of children suffering from stones in the urinary tract who, in addition to opaque stones, have structureless bodies which are not radio-opaque and consist of fibrin and a few cells. These might be the precursors of stones, but they nevertheless could occasion cause ureteric obstruction. He felt that in this kind of patient it might be worth putting a tube in the renal pelvis and irrigating with a fibrinolytic agent.

DR. CROSBIE pointed out that stones required a nidus oํㅛㅁ which to form and that this might be a fibrin deposi He thought it would be of interest to compare urokinast excretion in patients who form stones compared wi normal people. 